\title{
Jordanian Arabic: A Study of the Motivations for the Intentionality in Dialect Change
}

\author{
Ahmad M. Saidat \\ Department of English Language and Literature, Al-Hussein Bin Talal University, Jordan
}

\begin{abstract}
Language change and development is inevitable in any society due to social or structural factors. This research looks at Jordan, a small country that is experiencing an ongoing dialect change. Although this change is minor and arguably invisible, it is taking place among a large group of young people. In this study, the reasons and motivations for this change are unearthed. Over 200 people were interviewed and were asked to respond to a questionnaire. The collected data were then statistically analyzed. The findings were that social bending, identity, self-image, and network ties appear to be of the major reasons for young people imitating and adopting two regional dialects of the Middle East, namely Lebanese (LA) and Syrian (SA). The role of media appeared great and is probably the main source for the adoptions. There does not seem to be a strong adult rejection of this phenomenon which has become inevitable. The adoptions at this stage are intentional and are expected to develop to be unconscious in the future as younger receptors are not aware of the intentions of the current imitating groups and assumingly they will acquire certain vocabulary, tones, and structures as their mother dialect due to direct interaction with older teenagers. Historically, certain linguistic features disappeared from the local dialect of Jordan (JA) in favor of other neighboring dialects.
\end{abstract}

Index Terms - Arabic, language change, Jordanian dialect, social bending

\section{INTRODUCTION}

During the second war on Iraq in 2003, and after the capture of Saddam Hussein, Al-Aljazeera TV station (2008) invited Prince Hassan of Jordan. He talked then about the current situation within Iraq and the struggle between Sunni and Shi'a of Iraq and was afraid that certain world powers are the reason for "Lebanizing" Iraq. Although the word, Lebanizing may not be in the dictionaries of English, it came into existence during the civil war in Lebanon when the two groups- Sunni and Shi'a -fought for power. The term, since then, describes situations related to civil wars and to struggles between these two specific Muslim groups, and the Prince was worried that Iraqis would copy what had happened in Lebanon. In this study, I use the term to describe a language situation related to the LA and SA in that a process if copying certain features of these to dialects into (JA). It simply describes Lebanese and Syrian cultural and linguistic invasion of JA.

Arabic, as a Semitic language, has two main varieties, Modern Standard Arabic (MSA) and local Non-Standard Arabic (NSA). These have been exhaustively described and discussed in the literature, (Mahmoud, 2000, Belnap and Haeri. 1997, Agius 2007, Ani, 2007, Bahloul 2007, Benmamoun 2007, among many others). MSA is the official language of the Arab countries. NSA is the mother tongue variety which marks each country from the other. In the literature, these NSA dialects are categorized into five major groups Syro-Lebanese (Levantine Arabic) spoken in Jordan, Syria, Palestine and Lebanon; Arabian dialects spoken in Kuwait, Bahrain, Oman, UAE, Qatar, Yemen and Saudi Arabia; Mesopotamian dialects spoken in Iraq; Egyptian dialects spoken in Egypt; Moroccan dialects spoken in Mauritania, Morocco, Algeria, Tunisia and Libya.

While these dialects are grouped thus due to the similarities they have among them, there are notable grammatical, lexical, morphological and phonological differences that cannot be considered accent differences. However, despite these differences, each local NSA is accessible to the speakers of the same dialect group and less accessible and sometimes inaccessible to speakers of other groups. For example, a Jordanian would speak with a Syrian with ease, with a Saudi with less ease but would have challenging time with the Moroccan speakers. The dialects of concern in this paper are JA in opposition to LA and SA.

To this end, it has recently become evident that LA and SA are influencing other Arabic dialects including JA in many aspects such as semantically, phonologically and morphologically. However, in the current study, no the attempt is made to bring out the similarities and differences between LA/SA and JA instead I shall primarily describe and attempt to explain the sociolinguistic factors that had led and are leading to JA dialect change.

In the past few years, many radio and TV stations in Jordan as well as other Arab countries began to hire males and females from Lebanon to work in their stations as broadcasters of shows and other talk programs. The selection of broadcasters is, as most employers in this field do, dependent on education, personality and appearance. This seems fair for a job of this kind. However, what seems controversial is the selection based on the dialect of the applicant. A quick search over the internet would reveal a notable number of Lebanese TV and Radio broadcasters working in stations outside Lebanon. The majority of those TV and radio stations run shows in which MSA is not used. 
In the past, most stations would insist that a broadcaster was fluent in MSA, but today things seem to be different. A survey conducted by Hamadeh (2009) and published in Emirates Business 24/7 showed that Egyptian broadcasters were preferred over other broadcasters. In the survey a list of 150 broadcasters were considered for the competition. The top ten broadcasters were nine Egyptians and one Lebanese who came ninth in the list. It was noted; however, that those ten broadcasters run shows that use MSA and not any local dialect. Add to this, the survey did not show any viable control criteria and it did not mention where the survey took place, or the number of people surveyed. Hamadeh quotes an executive in a media buying agency saying,

"Individual efforts could be misleading, because they do not have enough funds to do the right sampling. TV meters are not available in the Arab World, which makes it less likely to achieve an accurate ranking. We have to be careful in relying on such studies while advising our clients to buy into a certain medium or specific TV program." And she quotes a media expert at Dubai Press saying, "This poses a serious question about the way audiences in the Arab World choose their viewership preferences and the creativity in TV programming."

Observation of Jordanian local and satellite TV and radio stations revealed that there was at least one Lebanese broadcaster in each station. Some of them had two-hour programs. Those broadcasters used LA in their programs. This, in fact, does pose a serious question, why were they hired although the Jordanian market had many competent alternatives? Yet, another question is: what distinguished those Lebanese broadcasters from their Jordanian peers?

Furthermore, the phenomenon of imitating neighboring Arabic dialects has expanded to cover daily conversations especially among the young. You can hear it at homes, schools and universities. Although the copied features of the other dialects are still very few, they mark the beginning of an inevitable dialect change.

In the coming sections, a survey of linguistic social theories of language change and similar cases of language change motivations are discussed.

\section{LITERATURE REVIEW}

\section{THEORIES OF LANGUAGE CHANGE AND MOTIVATIONS}

Dialectal change could be comparable to language change since we can assume that dialectal change is the first trigger to language change. There are many theories that attempt to justify and explain language change. These theories trace back to as early as the ancient time where there was a belief, according to the Bible, that Man has done so much wrong in their lives that God wanted to make their lives difficult by assigning each nation a language, in conclusion, they would suffer to understand each other (Genesis 11:1, 7, 8 and 9).

Another theory is the theory of language decay. A language with a complex structure is more likely to disappear in favor of a more flexible language (Mufwene, 2001). Greek and Latin for example decayed for the amount of declension and conjugation they had (Brenzinger, 1992).

Another theory claimed it was a natural process as languages tend to develop and evolve (Mufwene, 2001). They change slowly but eventually deviate from the original language through transitional periods (Harrington, 2006).

Another theory is the theory of social bending. This theory was developed by William Labov. Labov (1966), in his famous study in New York department stores, proved that the pronunciation of certain sounds reflected social class. For example, those who imitated the British pronunciation of the sound /r/ wanted to show that they come from high-class while those who pronounced the $/ \mathrm{r} /$ as in the American pronunciation came from a different social class. Labov was able to tell that certain people came from poor neighborhoods and pronounced the $/ \mathrm{r} /$ when they were at that part of the city which was known as a part for high-class customers. Evidence to this could also be found in the history of English during the French occupation of England. Some people imitated and used some of the French vocabulary as French at that time reflected people from high class. Words such as bon appétit, café, critique and many others are still used until today.

Social bending may affect all aspects of language, phonological, semantic, syntactic, morphological, or cognitive. Some theories claim the randomness of this phenomenon (Bright, 1998). However, sometimes this change or shift is intentional and systematic. Labov (1972), in his Martha's Vineyard study, noticed a phenomenon that the locals of Martha's Vineyard practiced. This is an island with primarily fishermen as inhabitants. Labov interviewed 69 people and found out that they intentionally deviated certain diphthongs from their original American pronunciation and that the deviation had to do with the attitudes of the speakers. It seemed that the fishermen wanted to distinguish themselves from other people, especially from those visiting the island in the summer time. By manipulating diphthongs, they believed that they are preserving their unique identity. Other inhabitants of the island adopted the fishermen's pronunciation and over time that dialect became the dialect of the island. What seemed to be intentional act carried out by a group of fishermen became a dialect by which the island is distinguished.

A good example of social bending is the case of the Multicultural London English. This form according to Kerswill et al. (2007) and Kerswill (2013) appeared in the late $20^{\text {th }}$ century. It is a dialect spoken by the working class in London and which had been imitated by a wide range of people. This dialect had put other dialects such as the Londoners' Cockney at risk of decay.

Igoudin (2011) conducted a case study on three young Asian girls who merged African American English Vernacular (AAEV) within their daily speech. She reached the conclusion that those girls believed that AAVE had benefits related 
to "hipness, popularity and cross-cultural socialization" (p. 1). She added, "In this process, code choice serves as a means to gain the subcultural capital and access the desired personal power and prestige among peers" (p. 1).

To this end, the two concepts that appear in most research are POWER and PRESTIGE. What power and what prestige do young people in Jordan seek, and why? What do they gain from imitating LA and SA? The case of the three Asian girls provides evidence that their choice was intentional and was not the result of acquisition. Rather, it seems more of learning and self-study. Future generations would not know that their parents learned a dialect intentionally for distinct reasons. They will probably acquire the new dialect and take it as their mother dialect.

Rampton (1995), from another angle, discussed the concept of crossing. He claimed that the crossing process is temporary showing that it is a means to build a social identity, an identity that breaks the barriers between different social groups depriving it from ethnical and racial differences. He contends that this linguistic crossing gave the speakers a message encoding power.

Eckert (1997) believes that "girls in high school are more socially constrained than boys" (p. 258). While according to Igoudin (2011) boys have many ways to shape up their identities, girls use language and dialect to do so.

In the current study, the social bending factors will be in focus with some examples of how these factors affect other linguistic aspects of JA. A Survey that was conducted by a popular dating site in Germany revealed that teenagers felt that certain dialects were more sensually and sexually provoking than others. They felt that these dialects could be a source of attraction to the opposite sex. The survey revealed that Bavarian was considered the most sensual. This provides evidence that language is a powerful source for bringing attention and attraction.

\section{Data, Methodology AND TheOretical Framework}

The major part of the data was collected from young people mainly from high school students and undergraduate university students. Another set of data were collected from older people to investigate their attitudes towards the dialectal change. The targeted population comprised 200 males and females. 100 were interviewed face to face while the other 100 were asked to respond for a questionnaire in writing without any identifying information other than age and gender. Tables 1 and 2 show the distribution of the participants.

TABLE 1:

THE DISTRIBUTION OF THE PARTICIPANTS: GENDER

\begin{tabular}{|l|l|l|}
\hline Gender & Number & Percentage \\
\hline Males & 57 & $28.5 \%$ \\
\hline Females & 143 & $71.5 \%$ \\
\hline
\end{tabular}

TABLE 2:

THE DisTRIBUtion OF THE PARTICIPANTS: AGE

\begin{tabular}{|l|l|l|}
\hline Age group & Number & Percentage \\
\hline $14-18$ & 62 & $31 \%$ \\
\hline $18-23$ & 92 & $46 \%$ \\
\hline Over 23 & 46 & $23 \%$ \\
\hline
\end{tabular}

The questionnaire type that was used was a mixed questionnaire. It consisted of an open-ended question that gave the chance to the respondents to express their feelings and give their opinions. It also contained closed-ended questions following the Likert scale. The open-end question was:

It has been noticed recently that some young people from the Jordanian society imitate LA and SA. If you have noticed this, please indicate whether you fall within this category and indicate the reasons why you do this, or others do it.

The data were then entered into SPSS for simple and basic statistical analysis of frequencies and to measure statistical significance. The responses were then tested against some theories of language attitude since the study of attitude is a millstone in understanding motivations and language choice.

Gardner and Lambert (1972) and Gardner (1985) contended that there are two major tasks for a speaker's selection of a certain language variety over the other,

1. Instrumental where the speaker makes his/her language choices to achieve a social benefit such as being considered part of anther social class. This choice can lead the speaker to feel that he/she comes from an upper social class or even from a lower social class depending where he/she finds it more beneficial for him/her.

2. Integrative where the speaker wants to be mingled and considered from another community.

Both of these tasks seem to be intentional leading to a crawling mutation in the language that one day will stand up and show in the form of a new language variety or even in the form of an entirely new language.

Aitchison (1994) explains that the change takes place in different manners such as decay, progress or neither this or that but inevitable. The case of dialectal change is not far from that of language change as some dialects of the same language could have apparent linguistic differences such as the case of Standard Arabic and local dialects. (Saidat, 2003)

\section{RESUlTS AND THE FINDINGS}


In this suction, the results are listed followed by a discussion and explanation of the findings.

1. $26 \%$ of female participants claimed that they imitate other dialects because they simply like them especially the Lebanese and the Syrian. These dialects, they say, are "nice and beautiful." However, they failed to provide answers why they thought they were nice and beautiful when they were asked if JA lacks beauty. They show more indulgence, they thought.

2. $43 \%$ of the participants claimed it was the culture where these dialects are used that attracted them. When they were asked about how adequate their knowledge about the Lebanese and Syrian cultures, they explained that they knew them through the media and that they had never lived in those countries. It seems that this group is influenced by the culture they see through the media in the forms of TV series and movies. They appear to have no idea about what the real practices of these countries are. The Lebanese and Syrian cultures are historically of the most respected cultures in the Middle East, and their practices are comparable to those in Jordan.

3. $22 \%$ thought that JA was inferior to its neighboring dialects. The participants failed to provide reasonable justification for such a belief. However, $64 \%$ of the participants, on the other hand, thought that JA is superior; and similarly failed to justify their beliefs. They attempted to defend their views showing a sense of patriotism and expressing their dissatisfaction with those who place JA in an inferior position compared to other dialects.

4. About $10 \%$ of the participants see that JA reflects harshness and Bedouinism, a quality not very much appreciated among young people today.

5. A large group of the participants, namely $72 \%$, thought that imitating LA and SA makes the individual feel like a better person in other peoples' eyes. They thought that by doing that they showed more flexibility and acceptability of the other. They saw it as an act of modesty and humanity, "When we use SA, we make refugees feel like home.' One participant explained.

6. $39 \%$ of the participants claimed that they imitate because they see their role-models in the speakers of LA and SA. One of the participants stated that "I feel jealous because Lebanese and Syrians are beautiful and easy-going. The way they speak is the source of their beauty!"

7. According to $90 \%$ of the participants, these two dialects show more passion and romance than JA. They see them as listener-friendly and flexible. These dialects, they believe, show that a person is free in terms of preserving traditions. They reflect high class and wealth. Furthermore, some participants thought that by imitating LA and SA, they were escaping from the local dialect and would be more involved in a world of high class and affection. An opposing group explained that LA and SA advocates were just mere imitators who give away their traditions to show fake identities that they desire but do not possess. They expressed their worries that these dialects which were intentionally imitated would become the mother dialect of their children or at least part of it. The majority of those participants advocating LA and SA considered these two dialects as more prestigious that are used to attracting more attention of males and females equally! They know, however, that doing this creates an artificial civilization and an unrealistic identity. They saw them as means of reflecting their way of thinking. In this regard, there is a widely held belief that language reflects thinking.

8. 38\% thought that these two dialects show sensuality; therefore, more people would be attracted to watch TV with Lebanese and Syrian series, movies or talk shows.

9. A minority of the participants, 5\%, said that some people would look down at you when they know that you were Jordanian due to the economic situation of the country. However, we cannot claim that Jordan has a worse economic status than Syria especially today.

10. $16 \%$ of the male participants claimed that they imitate them for the fun of the act of imitation. They explained that they imitate famous actors' and actresses' way of speaking for the purpose of mockery.

11. A large number of female participants, 83\%, thought that males liked Lebanese and Syrian females and the way they speak; therefore, they thought that Jordanian females wanted to compete with them and look as attractive as their Lebanese and Syrian counterparts by imitating their dialect. The remaining number, 17\%, of female participants thought that only girls with low self-esteem would imitate for reasons and benefits like that.

12. Male participants believed that LA and SA were the most sensual dialects with a percentage of $82 \%$. They, however, claimed that it occupies this status only when the speaker is a female. On the other hand, they believed that these two dialects were not suitable for male speakers as they pertain to the feminine aspect of the speaker. Some of this group of participants accused the local dialect of being tough and not desired by male listeners. They explained that they, as males, want to use the local dialect themselves, but would like to hear LA and SA from the opposite sex.

13. $14 \%$ of participants attributed the phenomenon of imitation to the lack of identity. They said, "Those who imitate are seeking identity, therefore, should go and live where they can find one." They added that the act of imitation was due to the lack of confidence in JA. They however, admit that "A person cannot find a job unless he or she has the good looks and the power of a sensual dialect."

14. "Lebanon is a country with evident abandonment of traditions," $32 \%$ of the participants claimed. However, they explained that the freedom sought relates to male and female equality and justice; and a means to deprive from the Islamic and Jordanian values. Therefore, Jordanian females want to feel this freedom and they find their only resort in the imitation of LA and SA. "I want to be respected. I am a devoted Muslim and to use some LA and SA does not deprive me from my devotion and faith." One female participant explained. At this stage, it is worth mentioning that 
women's rights are preserved in Jordan and that Jordan is one of the first countries in the Middle East to give women equal rights. It is even mandatory to have female members in the parliament.

15. $29 \%$ of the participants look at the situation from an unfamiliar perspective. Some females in Jordan think that they face a fierce competition from Syrian female counterparts whose numbers are increasing in the country due to the ongoing war in Syria and the substantial number of refugees who started to establish a life in Jordan. Others thought that this cultural invasion represented in the dialect is due to the weak Jordanian media. They accused the Jordanian official TV of allowing other TV stations to invade the houses and thinking of the Jordanian community. They claimed that most of the programs were not popular; therefore, people would go to other stations where they would find programs they liked. Add to this, most of the music on the local TV stations was either Egyptian or Lebanese and the national TV failed to meet the people's expectations.

\section{DisCUSSION OF THE RESUlTS AND FINDINGS}

It is partially true that speaking may reflect a person's way of thinking and by the same token, thinking may reflect the way a person speaks. The Sapir-Whorf Hypothesis (Key and Kempton, 1984) is probably one of the famous theories in this regard. This theory stressed the idea that thinking was greatly influenced by the person's native language. However, the question that needs to be answered is: would a change in the person's dialect alter or deviate his way of thinking? Or, does each dialect or language have a fixed or assumed way of thinking? In other words, does using what some people consider a 'sensual language' reflect sensual intentions? Do all the speakers of the 'sensual language' know that their language is seen as sensual? It would be prejudice to accuse all the speakers of a language to have the same way of thinking. Or even, to accuse a language or a dialect of limiting the thinking of its users.

This theory may have some truth to it; however, it remains weak in such a prospect. The attitudes of the speaker have strong influence on the way he speaks. Attitudes are subject to change and therefore the way of speaking as well. It is notable that those who imitate LA and SA dialects have different motivations and hence we cannot accuse them of having the same way of thinking. Rather, they have different attitudes. Saidat (2010) in his study of language attitudes in Jordan found that certain speakers used English and Arabic simultaneously to reflect class and good education, while others used standard Arabic to show good education and religious commitment. To sum up on this regard, attitudes motivate language choice but do not necessarily reflect a permanent way of thinking. We can notice that the adoption of LA and SA is both instrumental and integrative as explained by Gardner and Lambert (1972). The respondents were divided, although not equally, into two groups. One group wanted to achieve personal and self-benefits and the other group wanted to mingle and be part of the LA and Sa community. The latter group is significantly smaller that the former group, though.

Furthermore, a crucial factor that should not be overlooked is social networks. Language can be maintained when the ties between social networks are strong. Milroy (1980) and Milroy and Milroy (1985) showed that the strength of the social network played a great role in the maintenance of the language of that group. Depending on the strength of the ties, the language changes or is maintained. The size of the social network is yet another key factor that has a great impact on changing or preserving the norms. The larger the network is, the more the language is maintained. Jordan is a small country with a population of 9,500,000 people according to the 2016 census. The country has evident diversity due to the large numbers of refugees that come from Syria escaping the ongoing war. The number of Syrians exceeded $1,500,000$. And hence, we can consider them as a triggering factor to the dialect change.

Muysken (2010) stated that "Migration of large groups of speakers to another country, or to metropolitan regions in their own country where a different language is dominant, have produced a notable change in the language behavior of these speakers" (p. 7). He added "...smaller ethnic groups in a country where a language different from their own is dominant are under increasing pressure to adopt this dominant language” (p. 7). So, logically, the larger group should influence the change in the smaller group and not vice versa. This could provide evidence that the refugees in Jordan have little influence in the dialectical change in Jordan. This may also lead us to believe that the reasons underlying the imitation are stronger than the factor of face to face interactions.

A dialect shapes the cultural identity of its speakers. The situation in Jordan is very complex due to the area of the country and the number of inhabitants. There is a great diversity among the Jordanian society. For example, the country is divided into three main regions, the north, the middle and the south regions. Each region comprises governorates that have smaller cities urban and rural. Each governorate has a dialect or accent that distinguishes its speakers from other governorates and cities. In another categorization, Jordan's population is divided into the eastern bank Jordanians and western bank Jordanians in relation to the Jordan River. Those coming from the Palestinian side have also urban and rural origins and have dialectical differences. Add to this, the first decade of the $21^{\text {st }}$ century witnessed large numbers of refugees from Iraq and Syria who settled in the country and those, too, come from different dialectical backgrounds. The bottom line is that there seems to be no large and strong social network ties which leads us to believe that the populations as a whole is adaptable to change depending on their motivations and degree of acceptance to change. Clear evidence to this could be the rapid decay of the Bedouin dialect in Jordan.

The cultural invasion of a country can affect the language of that community. Some people may claim that the social media have little or no influence on language change due to the belief that the natural components of an interaction lack. 
(i.e. speaker-listener relationship) This, however, does not seem to be the case in Jordan. A number of words from the JA lexicon disappeared in favor of LA and SA words. Table (3) below lists some of these words and expressions.

TABLE 3.

JA WORDS TAKEN FROM LA AND SA

\begin{tabular}{|l|l|}
\hline JA & LA/SA \\
\hline /iHki ma?i:/ & /Hakini/ \\
\hline /ma baqdar/ & /ma fini:/ \\
\hline /keifak/ & /ki:fak/ \\
\hline /leish/ & /lashu:/ \\
\hline /istaneitak/ & /naTartak/ \\
\hline
\end{tabular}

Words like these in table (3) are now used by young people in closed communities that never had any interaction with Syrians or Lebanese. The only path that they found to get to Jordanians was through the media.

Another piece of evidence that words like those were adopted from social media is that Syria and Lebanon have themselves local dialects and to claim that Jordanians imitate all these dialects is infirm. In fact, it is that these imitations come from the same source dialects which would be the prominent dialects in these countries and in this case, they would be the main dialects used in the media. An observer of the Jordanian media would notice that the Ammani dialect is the prominent in the TV production and the same applies for Syria and Lebanon.

Some people face emotional conflicts when they start to notice that their mother dialect is changing and may have unpredictable reactions. They may show dissatisfaction towards their sons and daughters who are leading the change. Those people find their identity in their dialect and are not open to such a change. Their rejection, however, is not assumingly going to create a pulling force in front of the enthusiastic force of the youth. The majority of the older participants who were interviewed showed their rejection and satisfaction about the linguistic acts of the young. They, however, explained that they were, helpless.

In a report in the Los Angeles Times by Daniszewski (1997), an Aramaic speaker explained how he adopted Arabic instead of his mother tongue "fifty years ago all students in Malula spoke Aramaic, and some of them could speak Arabic with difficulty. Now all speak Arabic and some struggle with Aramaic."

Furthermore, some families started to have a dialect policy when they pass family laws that forbid the use of any non-JA. These laws might come into existence in a rational manner where the fathers and mothers ask their children to speak properly. Using Egyptian, for example, is taken by parents as if the child is trying to act funny, while using LA and SA is seen from a different angle.

Ferguson (1977) stated that "All language planning activities take place in particular sociolinguistic settings, and the nature and scope of the planning can only be fully understood in relation to the settings" (p. 9). To understand the underlying reasons for the current shift, we must comprehend the settings in which it is taking place. The current political situation of the region may provide some postulated justifications; however, the phenomenon had started before any refugee movements took place. The settings that require explanation can go back to as early as the beginning of the $21^{\text {st }}$ century. Nonetheless, when, where, and why does the imitation take place are probably the settings that require further investigation.

Another important dimension of the phenomenon is the age range of its users. We can notice that only young people practice it. People between the ages of 12 and 25 are the population in concern. We cane name it a young people's dialect since adults do not seem to use it. Nevertheless, we expect the age range to expand in the coming years to cover younger and older people. It is also notable that this group of young people uses some English along with JA and LA. It seems that they are developing a new language code that cannot be seen as copied from LA since French is the second or foreign language used in Lebanon.

We could, with caution, say that due to some negative societal and cultural views of Jordan and Jordanian, some of the locals are trying to escape these views. In a blog entitled "A devil's advocate view of Jordan" (unknown: 2009), it can be observed from the main article and comments, that Jordan is seen as a $2^{\text {nd }}$ grade country. This could lead us to believe that the young are trying to escape this view by any means. The one means to escape such views at no cost is language.

\section{CONCLUSION}

To tackle this phenomenon, we need to look and consider several issues namely its practices, its beliefs, and its users. Any new practice of a community must result from advantages that users obtain. In the case of a language or a dialect, a user would learn a second language because he finds some benefits in doing so. For example, if we measure the benefits from learning English compared to Russian, we would, without caution, select English as speaking and knowing English have more benefits compared to Russian. English is the most widely used language in the world in education, business, medicine, politics, etc. While Russian, although one of the official languages of the United Nations, does not have the same status of English. Hence, learning English is justified, we simply need it. Therefore, we expect that those who learn English have good reason to do so. And by the same token, those who select Russian have their own good reasons too. Furthermore, users of LA and SA in the Jordanian community must have their justification for their choice. Radio stations and employers, too, must have theirs. 
Furthermore, the factor of age plays a great role in language choice. The study population was solely between the ages of 16 and 22. Their attitudes are immature and are subject to change. The imitation process they are carrying out may come to an end. However, certain aspects may resist and remain unchanged and eventually become a norm.

Using LA or SA is connected to sensual connotations. Spolsky (2004) explained that "China recently passed a new language law that bans the use of foreign words and the misuse of Chinese. According to the law, Putonghua is to be the officially legal language of China, its standard spelling and pronunciation to be required of all the radio announcers, teachers and civil servants" (p. 2).

Moreover, even among their peers, those who imitate other dialects face criticism or at least are shown some dissatisfaction of what they are practicing. We notice that at the community level, this phenomenon has rejection by some members; however, on the national level it is not even noted.

Ironically, by laws of nature, those who try to change the norms of a certain group are abandoned and sometimes exiled. In the current case of this study, it seems that the leaders of the change are selected and preferred over the others. This could lead us to believe that any rejection of Lebanizing the JA is artificial. Broadcasters and employers believe that this dialect is nationally desired. This national acceptance definitely is underlain by some serious goals that relate to the psychology and mentality of the local employers and marketers.

Spolsky (2004) explained that "language evolution is to be explained not just by small random variation strengthened by geographical isolation, but also by including functional and social selection" (p. 7). The change in the JA must be the result of the disadvantages the local dialect has and advantages the newly adopted dialect has. We can carry a comparative linguistic study and describe and explain the syntactic, morphological and phonological adoptions but the underlying reasons for the adoption itself remain the most crucial factor that require extensive research.

What is being investigated here is the beginning of a dialect change and by no means is exaggerated. We do not assume the complete decay of a dialect in favor of another. However, the future remains tomorrow.

\section{REFERENCES}

[1] Agius, Dionisius A. (2007). Who spoke Siculo-Arabic? XII Incontro Italiano di Linguistica Camito-semitica, ed. Marco Moriggi, 25-33. Soveria Mannelli: Rubettino.

[2] Aitchison, J. (1994). Language change: progress or decay? (pp. 627-637). Macmillan Education UK.

[3] Al-Ani, Salman H. (2007). The linguistic analysis and rules of pause in Arabic. Approaches to Arabic Linguistics: Presented to Kees Versteegh on the Occasion of his Sixtieth Birthday, ed. Everhard Ditters, Harald Motzki, 209-244. Leiden: Brill.

[4] Aljazeera. (2008). Leqa' Alyawm: azamat almentaqa wa malameh almustaqbal with Al-Hassan ibn Talal. http://www.aljazeera.net/programs/today-interview/2008/3/3. Access date: December 10th, 2013.

[5] Bahloul, Maher. (2007). Linguistic diversity: The qaaf across Arabic dialects. Perspectives on Arabic Linguistics XIX: Papers from the Nineteenth Annual Symposium on Arabic Linguistics, Urbana, Illinois, April 2005, ed. Elabbas Benmamoun. Amsterdam: Benjamins.

[6] Belnap, Kirk, Niloofar Haeri. (1997). Structuralist studies in Arabic linguistics: Charles A. Ferguson's papers, $1954-1994$. Leiden, New York.

[7] Benmamoun, Elabbas (ed.). (2007). Perspectives on Arabic Linguistics XIX: Papers from the Nineteenth Annual Symposium on Arabic Linguistics, Urbana, Illinois, April 2005. Amsterdam: Benjamins.

[8] Brenzinger, Matthias. (1992). Language Death: Factual and Theoretical Explorations with Special Reference to East Africa. Walter de Gruyter. New York.

[9] Bright, William. (1998). Social Factors in Language Change. In Coulmas, Florian (1998). The Handbook of Sociolinguistics. Blackwell Reference Online. DOI: 10.1111/b.9780631211938.1998.0007.x

[10] Daniszewski, John. (1997). Syrian Tries to Resurrect Language Spoken by Jesus. http://articles.latimes.com/1997-0329/news/mn-43272_1_arabic-language March 29 1997. Accessed on February 28, 2016.

[11] Eckert, Phyllis. (1997). The whole woman: Sex and gender differences in variation. In Sociolinguistics: A Reader and Coursebook, Nikolas Coupland and Adam Jaworski (eds.), 212-228. New York: St. Martin's Press.

[12] Ferguson, C. A. (1977). Sociolinguistic settings of language planning. Language planning processes, 21: 9-29.

[13] Hamadeh, Dima. (2009). Egyptians are Arab televisions' favourite presenters, says survey. Emirates Business 24/7 (2009). http://www.emirates247.com/eb247/companies-markets/media/egyptians-are-arab-televisions-favourite-presenters-says-survey2009-04-12-1.96846.

[14] Harrington, Jonathan. (2006). "An Acoustic Analysis of 'Happy Tensing' in the Queen's Christmas Broadcasts". Journal of Phonetics 34 (4): 439-57. doi:10.1016/j.wocn.2005.08.001.

[15] Igoudin, A. L. (2011). Asian American girls who speak African American English: A subcultural language identity. In Du Bois, Inke, and Nicole Baumgarten (Eds.), Multilingual Identities: New Global Perspectives. Berlin: Mouton de Gruyter.

[16] Gardner, R. (1985). Social psychology and second language learning. The role of attitudes and motivation. London: Edward Arnold.

[17] Gardner, R. C. \& Lambert, W. E. (1972). Motivational variables in second language acquisition. In R. C. Gardner \& W. Lambert (eds.) Attitudes and motivation in second language learning. (pp. 119-216). Rowley, MA: Newbury House.

[18] Kerswill, Paul. (2013). Identity, ethnicity and place: the construction of youth language in London. In: Auer, Peter, Hilpert, Martin, Stukenbrock, Anja and Szmrecsanyi, Benedikt, (eds.) Space in language and linguistics. Linguae and Litterae. Walter de Gruyter, pp. 128-164.

[19] Kerswill, P., Cheshire, J., Fox, S., Khan, A., \& Torgersen, E. (2007). Multicultural London English: the emergence, acquisition and diffusion of a new variety. ESRC Research grant RES, 62 (23), 0814.

[20] Kay, P., \& Kempton, W. (1984). What is the Sapir - Whorf hypothesis? American anthropologist, 86(1), 65-79. 
[21] Labov, W. (1966). The Social Stratification of English in New York City. Washington: Center for Applied Linguistics.

[22] Labov, William. (1972). Sociolinguistic Patterns. Philadelphia: University of Pennsylvania Press.

[23] Mahmoud, Abdulmoneim. (2000). Modern Standard Arabic vs. Non-Standard Arabic: Where Do Arab Students of EFL Transfer From? Language, Culture and Curriculum, Volume 13, Issue 2, pages 126 - 136

[24] Matar, Dina. (2007). Heya TV: A Feminist Counterpublic for Arab Women? Comparative Studies of South Asia, Africa and the Middle East 2007 27(3):513-524.

[25] Milroy, J., \& Milroy, L. (1985). Authority in language. Investigating Language Prescription and Standardisation. London/New York.

[26] Milroy, Lesley. (1980). Language and social networks. London; Baltimore: Basil Blackwell; University Park Press.

[27] Mufwene, S. S. (2001). The ecology of language evolution. Cambridge University Press. UK.

[28] Muysken, P. (2010). 13 Scenarios for Language Contact. The handbook of language contact, 265-281. In Hickey, R. (2010). The handbook of language contact. John Wiley \& Sons.

[29] Rampton, B. (1995). Language crossing and the problematisation of ethnicity and socialisation. Pragmatics, 5(4). 485-513.

[30] Saidat, A. M. (2003). A sociolinguistic comparison of the syntax of modern standard Arabic and Jordanian Arabic. A Master's Thesis. The University of Texas at Arlington.

[31] Saidat, A. M. (2010). Language Attitude: The case of Jordan. International Journal of Academic Research, 2(6). $235-243$.

[32] Spolsky, B. (2004). Language policy. Cambridge University Press. UK.

[33] Thomason, Sarah Grey and Terrence S. Kaufman. (1988). Language contact, creolization and genetic linguistics. Berkeley: University of California Press.

[34] Unknown. (2009). A devil's Advocate view of Jordan. Iraatus. January 28, 2009 http://iraatus.blogspot.com/2009/01/jordan-istiny-poor-and-it-stinks-give.html. Access date: January $7^{\text {th }}, 2016$.

Ahmad Mahmoud Saidat is an associate professor of linguistics in the department of English language and literature at AlHussein bin Talal University. He graduated from the University of Texas at Arlington in 2006. His research interests include syntax, morphology, language attitude and change, and sociolinguistics. 